\title{
User-Fees in Health Services: Assessing how it Impacts on Access, Utilization and Quality of Care in a Tertiary Health Facility in Delta State, Nigeria
}

\author{
Ejughemre Ufuoma John*, Ivrogbo Stanley \\ Department of Community Medicine Delta State University Teaching Hospital P.M.B 07, Oghara, Delta State, Nigeria \\ *Corresponding author: ufuoma.ejughemre@delsuth.com.ng
}

Received April 29, 2014; Revised June 09, 2014; Accepted June 15, 2014

\begin{abstract}
Objective: To assess how user-fees policy impacts on clienteles' access to care, willingness to utilize health services and their satisfaction with the quality of healthcare, having to pay at the point of service in a tertiary health facility. Method: This was a cross-sectional descriptive study. The instrument was a pre-tested, semistructured self administered questionnaire. Descriptive statistics as well as chi-square test and regression analysis were done to show statistically significant associations. Results: The findings reveal different modes money was made available for payment for health services. On the whole, about $98 \%$ of payment were through 'formal' out-of pocket spending (user-fees) with most respondents having to source for funds from own money. It was shown that user-fees increases 'rational' demand for services and at the same time decreasing the willingness to seek such level of care. However, it is associated with better quality service delivery. Conclusion: The findings from this study has brought to the fore that user-fee policy is an effective mechanism for achieving desired health outcomes in tertiary care. However, there remain the problems of inequities in tertiary healthcare coverage. The evidence so far suggests that user fees alone will not accomplish the sustainability objectives in health financing in the country. This suggests that charges levied for tertiary health services should therefore be linked to the broader package of financing through health insurance coverage.
\end{abstract}

Keywords: user-fees, access, utilization, quality, tertiary health services, Nigeria

Cite This Article: Ejughemre Ufuoma John, and Ivrogbo Stanley, "User-Fees in Health Services: Assessing how it Impacts on Access, Utilization and Quality of Care in a Tertiary Health Facility in Delta State, Nigeria." American Journal of Public Health Research, vol. 2, no. 4 (2014): 119-124. doi: 10.12691/ajphr-2-4-1.

\section{Introduction}

Efforts made to achieve universal access to health care delivery rejuvenated concerns about sustainable health care financing in many low-resource countries such as Nigeria. [1,2] These concerns necessitated raising several options to finance health services in these countries. Of the available options, evidence reveals the scaling-up of cost-sharing mechanisms such as the user-fees policy in health services. [3] Remarkably, these fees (sometimes referred to as formal out-of-pocket spending) are formal charges levied or payments made at the point of use for any aspect of health services, and they may be charged as consultation fees, fees for drugs and medical supplies or charges for any health service rendered, such as outpatient or inpatient care [1,3].

In Nigeria for instance, user fees policy was introduced as a mode of financing government's health services within the framework of the Bamako initiative of 'revolving drug funds'. [4] Of note is that this financing policy and drug revolving funds are inter-linked. User-fee policy was debatably in response to the unrelenting struggle in financing health services in the country, as with most countries in the sub-Saharan African region. [4] This policy became important following the decline in the Nigerian government's budgets in real terms in response to macroeconomic problems with escalating demand for health services, partly because of population growth, thriving social mobilization and increasing demand for health care delivery [5] Nevertheless, the institution of user fee policy created debates of the impacts of the policy on healthcare delivery. This is because, efforts geared towards achieving universal health coverage requires steps aimed at reducing barriers, particularly economic, financial or cultural barriers, as well as those relating to the demand for health care. However, some analysts and donors agencies have argued that introducing national user fee at all levels of health services delivery will among many other things reduce budget deficits in planning for national health systems while scaling up the quality of health care [6,7] More so, proponents posit that user-fee policy will improve efficiency in utilization of services by diminishing 'frivolous' consumption of health services, through rational utilization of these services. $[6,7,8]$ Notwithstanding, there are views that the introduction of user fees in health services is a diametrical opposition towards the actualization of universal health coverage. [9] The dispute is that the excessive reliance on these fees 
decreases demand for healthcare, 'scales-up' inequitable access to quality care, and exposes households to the financial risk of expensive illness at the time of need. Hitherto, several campaigns $[10,11]$ have advocated the removal of user fees. Still, the debates about this policy have been so contentious with proponents and detractors advancing their arguments. Despite the importance of these debates, there is still paucity of research evidence of this policy in Nigeria. Some other developing countries like Tanzania, Uganda and Rwanda have detailed studies on user-fees policy [1], however, the reverse is the case in Nigeria. Although, some authors [12,13] have attempted to provide evidence in view, there is still the need to provide an updated research evidence with emphasis on service delivery. More so, the growing need for tertiary health services and the underpinning of demand-driven health service delivery in the Nigerian health market necessitates the need to provide evidence for health care delivery. Consequently, this study therefore tries to show how user-fees impacts on clientele accessing care, their willingness to utilize services and satisfaction with the quality of healthcare based on payment at the point of service, by using a tertiary health centre in Delta State, Nigeria. However, it is not within the scope of the study to show the effectiveness of user-fees on changes in access, utilization rates or changes in outcomes based on the quality of care given.

\section{Methods}

The study was a descriptive cross-sectional study, and it was conducted between the months of February to April, 2014. The study population consisted of all out-patients requiring specialist attention in the Delta State University Teaching hospital Oghara; a tertiary health facility in a semi-urban community in Ethiope West Local Government Area of Delta State. The rationale behind this choice was to secure enough similarities in terms of contexts (e.g. population coverage by such level of care) and constraints (e.g. level of development of tertiary health system). A simple random sampling technique was undertaken to sample 459 respondents from the medical, surgical, and obstetrics and gynaecological out-patient departments (OPDs) of the hospital. This was calculated by using the utilization (clinic attendance) rates per month for patients in these OPDs. The paediatric OPD was excluded due to the problem of getting informed consent from children besides patients attending the family medicine outpatient clinic.

The study instrument was a pre-tested, semi-structured self-administered questionnaire. The questionnaire schedule elicited information in respect of the demographic characteristics of the respondents: age, sex, tribe, marital status, income status, type of occupation. The ability to access and to pay for quality health services in the facility by respondents was assessed by questions which included: (i) "How long does it take you to get to this hospital from your place of residence?”, (ii.) How do you pay for healthcare rendered to you?" (iii.) "Has not having enough money affected your seeking health care in this hospital?” On utilization of services questions included: (i) How often do you visit this facility for treatment in a year? (ii.) Do you feel that the way you have to pay for care makes you seek care when necessary? On the quality of care, questions included: (i.) "How satisfied are you with the time spent waiting to be attended to by the doctor?" (ii.) "What is your view of the attitude of the health workers in the hospital?" (iii.) "How satisfied are you with the charges for the services rendered in this facility with the performance of the healthcare providers?" (iv.) Do you get the kind of care you desire and do you get your desired health state? The data generated were analysed using statistical package for scientific solutions (SPSS 16.0 version). Chi-square test and regression analysis were used to assess the associations between variables, and the associations were considered significant at $\mathrm{p}<0.05$. Ethical approval was obtained from the health ethics and research committee of the Delta State University Teaching Hospital Oghara.

\section{Results}

The results of the study were obtained from 459 clienteles visiting the OPDs of medical, surgical, obstetrics and gynaecological departments for specialists' health care in Delta State University Teaching Hospital.

\subsection{Demographic Characteristics of Respondents}

Findings from the study showed that the average age of the respondents was 36.48 years with a standard deviation of 12.51. The majority of them were females 297 (64.7\%) with a male: female ratio of $0.54: 1$ and the majority of the respondents were married (65.6\%), while 33.1\% were single and approximately $1 \%$ were either divorced, cohabiting or widowed. Findings showed that of those employed; those working in government services (civil and public servants) were the majority at $27.2 \%$, private employees at $23.5 \%$, traders $15.0 \%$ and farmers at $4.1 \%$ of the total occupational status respectively. However, a significant proportion of the respondents were unemployed at $29.6 \%$. More so, the results of their average monthly income showed that most of the respondents (41.3\%) earned less than $\$ 18,000$ (109 USD) per month which is the approved minimum pay in the public service in Nigeria, see Table 2.

Table 1. Demographic characteristics of respondents

\begin{tabular}{|c|c|c|}
\hline Characteristics & Frequency & $\begin{array}{c}\text { Percentage } \\
(\%)\end{array}$ \\
\hline Sex & & \\
\hline Male & 161 & 35 \\
\hline Female & 298 & 65 \\
\hline Total & 459 & 100 \\
\hline Marital Status & 152 & 33.1 \\
\hline Single & 301 & 65.6 \\
\hline Married & 2 & 0.4 \\
\hline Divorced & 2 & 0.4 \\
\hline co-habiting & 2 & 0.4 \\
\hline Others & 459 & 100 \\
\hline Total & Standard Deviation & \\
\hline (36.48) & $(12.51)$ & \\
\hline Mean Age of respondents & & \\
\hline & & \\
\hline
\end{tabular}


Table 2. Occupation and estimated monthly income

\begin{tabular}{|c|c|c|}
\hline Occupation & Frequency & Percent (\%) \\
\hline Farmer & 19 & 4.1 \\
\hline Trader & 69 & 15.0 \\
\hline government services & 125 & 27.2 \\
\hline private service & 108 & 23.5 \\
\hline Unemployed & 136 & 29.6 \\
\hline Total & 459 & 100 \\
\hline Income Status & & \\
\hline less than $N 18,000$ & 189 & 41.2 \\
\hline 18,000 to 45,000 & 131 & 28.5 \\
\hline 45,000 to 100,000 & 109 & 23.7 \\
\hline N 100,000 & 31 & 6.8 \\
\hline Total & 459 & 100 \\
\hline
\end{tabular}

Note: $165: 00=1$ USD

\subsection{Mode of Funding for Health Care}

On the mode of funding for health services in the facility, it was found out that there were different modes money was made available for payment. The results revealed that this was through own money (personal sources), contributions from relations or friends, borrowed money and via pre-payments (health insurance). While most of them did this from their own source at $49 \%$, others had to make a combination of these with own sources plus contributions at $20.7 \%$ and own sources plus contributions plus borrowed monies at $16.3 \%$.

Table 3. Mode of funding payment for health services

\begin{tabular}{|c|c|c|}
\hline Mode of funding health services & Frequency & Percent \\
\hline Own money & 225 & 49.0 \\
Contributions & 126 & 27.5 \\
Borrowed & 94 & 20.5 \\
Health insurance & 14 & 3.0 \\
\hline Total & 459 & 100.0 \\
\hline
\end{tabular}

\subsection{Impact of User-fees on Accessing Health Services}

It was shown that the user-fees policy impacts negatively on the willingness to access/seek tertiary health services, as $60.7 \%$ of respondents were not willing to access health care due to difficulty in sourcing funds to pay directly for health services see Table 4 . In fact, $73.2 \%$ found it difficult to pay for needed health care services as the main payment pattern was via user-fees. Additionally, a regression analysis model for the methods of sourcing funds for paying for services (independent variables) and having financial difficulty in paying for healthcare services (dependent variable) showed that of the various methods of sourcing funds for paying for services; borrowed monies $(\beta=-.909$; SE $=.173, \mathrm{p}=.001)$ and contributions from relatives $(\beta=-.206$; $\mathrm{SE}=.096, \mathrm{p}=.032)$ were the main contributions to the reason for not seeking tertiary health services in the facility. More so, other factors which contributed negatively to the decision in seeking health care were marital status (being married) ( $\beta=460 ; \mathrm{SE}=.197, \mathrm{p}=.019$ ) and monthly income (lower income $)(\beta=.262 ; \mathrm{SE}=.110, \mathrm{p}=.018)$ after a regression analysis was done.

Table 4. Has not having enough money affected your seeking healthcare

\begin{tabular}{|c|c|c|}
\hline & Frequency & Percent (\%) \\
\hline Yes & 279 & 60.7 \\
\hline No & 182 & 39.3 \\
\hline Total & 459 & 100 \\
\hline
\end{tabular}

Table 5. Modes of paying for health services the willingness to seek healthcare (logistic regression)

\begin{tabular}{|c|c|c|c|c|c|c|c|c|}
\hline \multirow[t]{2}{*}{ Variables } & \multirow[t]{2}{*}{$\beta$} & \multirow{2}{*}{$\begin{array}{l}\text { S. } \\
\text { E. }\end{array}$} & \multirow[t]{2}{*}{ Wald } & \multirow{2}{*}{$\begin{array}{l}d \\
f\end{array}$} & \multirow{2}{*}{$\begin{array}{c}\mathrm{p}- \\
\text { valu } \\
\mathrm{e}\end{array}$} & \multirow{2}{*}{$\begin{array}{c}\operatorname{Exp}( \\
\beta)\end{array}$} & \multicolumn{2}{|c|}{$\begin{array}{l}95.0 \% \\
\text { C.I.for } \\
\operatorname{Exp}(\beta)\end{array}$} \\
\hline & & & & & & & $\begin{array}{c}\text { Low } \\
\text { er }\end{array}$ & $\begin{array}{c}\text { Upp } \\
\text { er }\end{array}$ \\
\hline $\begin{array}{c}\text { Own } \\
\text { Money }\end{array}$ & $\begin{array}{c}- \\
1.33 \\
2\end{array}$ & $\begin{array}{c}.40 \\
6\end{array}$ & $\begin{array}{c}10.7 \\
87\end{array}$ & 1 & $\begin{array}{c}.00 \\
1\end{array}$ & .264 & .119 & .584 \\
\hline Borrowed & $\begin{array}{c}- \\
.399 \\
\end{array}$ & $\begin{array}{c}.12 \\
1 \\
\end{array}$ & $\begin{array}{c}10.8 \\
95 \\
\end{array}$ & 1 & $\begin{array}{c}.00 \\
1 \\
\end{array}$ & .671 & .530 & .850 \\
\hline $\begin{array}{c}\text { Contributi } \\
\text { ons }\end{array}$ & $\begin{array}{c}- \\
.101 \\
\end{array}$ & $\begin{array}{c}.08 \\
1 \\
\end{array}$ & $\begin{array}{c}1.52 \\
4 \\
\end{array}$ & 1 & $\begin{array}{c}.21 \\
7 \\
\end{array}$ & .904 & .771 & $\begin{array}{c}1.06 \\
1 \\
\end{array}$ \\
\hline $\begin{array}{c}\text { Health } \\
\text { Insurance }\end{array}$ & .109 & $\begin{array}{c}.20 \\
4\end{array}$ & .288 & 1 & $\begin{array}{c}.59 \\
2\end{array}$ & $\begin{array}{c}1.11 \\
5\end{array}$ & .748 & $\begin{array}{c}1.66 \\
3\end{array}$ \\
\hline
\end{tabular}

\subsection{Impact of User-fees on Utilizing Health Services}

On utilizing the available health services by clientele in the facility, the policy of having to pay directly for each service provided or recommended, also impacts on the ability and decision to use any of such services. While the study showed that most respondents $(69.7 \%)$ were willing to pay for all services that were recommended to improve their health outcomes, however, majority of the respondents had difficulty in the utilizing all of the needed services because of the policy of having to pay from their own pockets. For instance, Table 6 shows that $73.2 \%$ of the respondents had it difficult in paying for health services in the hospital. Findings from a regression analysis to show the contribution of how each mode of payment for services impact on the use of service delivery showed that own money $(\beta=-1.332 ; \mathrm{SE}=.406, \mathrm{p}=.001)$ and borrowed money $(\beta=-.399 ; \mathrm{SE}=.121, \mathrm{p}=.001)$ contributed significantly to the difficulty in clientele utilizing all recommended services even when they knew that it will lead to better management and outcome.

Table 6. Is it difficulty paying for the services utilized in this hospital

Table 6. Is it difficulty paying for the services utilized in this hospital
\begin{tabular}{|c|c|c|}
\hline & Frequency & Percent (\%) \\
\hline yes & 336 & 73.2 \\
\hline no & 123 & 26.8 \\
\hline Total & 459 & 100 \\
\hline
\end{tabular}

Table 7. Modes of paying for health services \& the decision to utilize services (logistic regression)

\begin{tabular}{|c|c|c|c|c|c|c|c|c|}
\hline \multirow{2}{*}{ Variables } & \multirow{2}{*}{$\beta$} & \multirow{2}{*}{$\begin{array}{c}\text { S.E } \\
\cdot\end{array}$} & \multirow{2}{*}{ Wald } & \multirow{2}{*}{$\begin{array}{l}D \\
f\end{array}$} & \multirow{2}{*}{$\begin{array}{c}\mathrm{p}- \\
\text { valu } \\
\mathrm{e}\end{array}$} & \multirow{2}{*}{$\begin{array}{c}\operatorname{Exp} \\
(\beta)\end{array}$} & \multicolumn{2}{|c|}{$\begin{array}{l}\text { 95.0\% C.I. } \\
\text { for } \operatorname{Exp}(\beta)\end{array}$} \\
\hline & & & & & & & $\begin{array}{c}\text { Low } \\
\text { er }\end{array}$ & $\begin{array}{l}\text { Upp } \\
\text { er }\end{array}$ \\
\hline $\begin{array}{l}\text { Own } \\
\text { money }\end{array}$ & $\begin{array}{c}- \\
1.33 \\
2\end{array}$ & $\begin{array}{l}.40 \\
6\end{array}$ & $\begin{array}{c}10.7 \\
87\end{array}$ & 1 & .001 & .264 & .119 & .584 \\
\hline $\begin{array}{c}\text { Borrowed } \\
\text { money }\end{array}$ & $\begin{array}{c}- \\
.399 \\
\end{array}$ & $\begin{array}{c}.12 \\
1 \\
\end{array}$ & $\begin{array}{c}10.8 \\
95 \\
\end{array}$ & 1 & .001 & .671 & .530 & .850 \\
\hline $\begin{array}{l}\text { Contributi } \\
\text { ons }\end{array}$ & $\begin{array}{c}- \\
.101\end{array}$ & $\begin{array}{c}.08 \\
1\end{array}$ & $\begin{array}{c}1.52 \\
4\end{array}$ & 1 & .217 & .904 & .771 & $\begin{array}{c}1.06 \\
1\end{array}$ \\
\hline $\begin{array}{c}\text { Health } \\
\text { Insurance }\end{array}$ & .109 & $\begin{array}{c}.20 \\
4\end{array}$ & .288 & 1 & .592 & $\begin{array}{c}1.11 \\
5\end{array}$ & .748 & $\begin{array}{c}1.66 \\
3\end{array}$ \\
\hline
\end{tabular}

Cox \& Snell R Square $=.068$ Nagel kerke R Square $=.097$

\subsection{Impact on Quality of Health Services}

Respondents had varying views of the quality of care being received in the hospital. The study tried to assess clienteles' (respondents') satisfaction (or perception) of the quality of care given in the tertiary health facility in relation to the user-fee policy. These were on satisfaction 
with patient's waiting time, attitude of health care workers, on effectiveness in terms of the perceived outcome(s), and the overall perception with the services being provided in meeting their health needs based on having to pay directly for services most of the time. Accordingly, the findings revealed that $37.1 \%$ of the respondents were dissatisfied with the waiting time to see a health care provider (usually the doctor) even though they had to pay for the services directly, while $32.7 \%$ were satisfied and $28.3 \%$ were indifferent. However, 39\% felt satisfied with amount of money being payed at the point of service for the kind of care received. This constituted the majority of the respondents who were satisfied with the charges for the kind of care being given as $25 \%$ were indifferent and the rest being dissatisfied. The association between payment patterns and satisfaction with the care given for paying at the point of service was statistically significant $\left(\mathrm{X}^{2} \mathrm{p}-\right.$ value $=0.001)$. The perception was that paying for such services at the point of care increases the likelihood of better health outcome. In fact, about $83 \%$ of those surveyed believed that the quality of care provided increases the likelihood of improved health outcomes despite that they had to pay from out-of-pocket. More so, the study showed that a higher percentage (42.6\%) felt satisfied with health care providers' attitude when compared with those who were not (32.6\%). However, it was difficult to show if the association was statistically significant. Notwithstanding, the overall perception of the performance of health care providers was high with $62.1 \%$ being satisfied. It was shown that payments being made at the point of service by different modes of sourcing for money were associated with higher satisfaction with the performance of service delivery (quality of care). The findings showed that borrowed funds and contributions were associated with receiving better care and these were statistically significant at $(\beta=460 ; \mathrm{SE}=.197, \mathrm{p}=.019)$ and ( $\beta=460 ; \mathrm{SE}=.197, \mathrm{p}=.019)$ respectively.

Table 8. Payment patterns for health services \& the quality of care (logistic regression)

\begin{tabular}{|c|c|c|c|c|c|c|c|c|}
\hline \multirow{2}{*}{ Variables } & & \multirow{2}{*}{$\begin{array}{c}\text { S.E } \\
.\end{array}$} & \multirow{2}{*}{$\begin{array}{c}\text { Wal } \\
\mathrm{d}\end{array}$} & \multirow{2}{*}{$\begin{array}{l}\mathrm{d} \\
\mathrm{f}\end{array}$} & \multirow{2}{*}{$\begin{array}{c}\text { Sig } \\
.\end{array}$} & \multirow{2}{*}{$\begin{array}{c}\operatorname{Exp}( \\
\beta)\end{array}$} & \multicolumn{2}{|c|}{$\begin{array}{c}\text { 95.0\% C.I.for } \\
\operatorname{EXP}(\beta)\end{array}$} \\
\hline & & & & & & & $\begin{array}{l}\text { Lowe } \\
\mathrm{r}\end{array}$ & $\begin{array}{c}\text { Uppe } \\
\text { r }\end{array}$ \\
\hline $\begin{array}{c}\text { Own } \\
\text { Money }\end{array}$ & $\begin{array}{c}.45 \\
6 \\
\end{array}$ & $\begin{array}{l}.29 \\
9 \\
\end{array}$ & $\begin{array}{c}2.31 \\
5 \\
\end{array}$ & 1 & $\begin{array}{c}.12 \\
8 \\
\end{array}$ & 1.577 & .877 & $\begin{array}{c}2.83 \\
6 \\
\end{array}$ \\
\hline Borrowed & $\begin{array}{c}.23 \\
6 \\
\end{array}$ & $\begin{array}{c}.11 \\
1 \\
\end{array}$ & $\begin{array}{c}4.51 \\
4 \\
\end{array}$ & 1 & $\begin{array}{c}.03 \\
4 \\
\end{array}$ & 1.266 & 1.018 & $\begin{array}{c}1.57 \\
4\end{array}$ \\
\hline $\begin{array}{c}\text { Contributi } \\
\text { on }\end{array}$ & $\begin{array}{c}.19 \\
4\end{array}$ & $\begin{array}{l}.07 \\
5\end{array}$ & $\begin{array}{c}6.71 \\
8\end{array}$ & 1 & $\begin{array}{c}.01 \\
0\end{array}$ & 1.215 & 1.049 & $\begin{array}{c}1.40 \\
7\end{array}$ \\
\hline $\begin{array}{c}\mathrm{H} . \\
\text { Insurance }\end{array}$ & $\begin{array}{c}.09 \\
6 \\
\end{array}$ & $\begin{array}{c}.15 \\
1 \\
\end{array}$ & .404 & 1 & $\begin{array}{c}.52 \\
5 \\
\end{array}$ & 1.101 & .819 & $\begin{array}{c}1.48 \\
1\end{array}$ \\
\hline
\end{tabular}

Cox \& Snell R Square =. 041 Nagel kerke R Square =. 055

\section{Discussion}

As policy debates about user fees have remain contentious, with proponents and detractors advancing their arguments, designing policy reforms for improving health care financing in Nigeria as well as other developing countries requires valid and reliable evidence. This has become necessary because efforts geared towards achieving universal health coverage (the key objective of the world health organization) necessitates sustainable and equitable health financing mechanisms. Although, progressive evidence is considered necessary for financing policy reforms [14], however; an overview of the literature reveals paucity of evidence of the debates regarding user-fees in health care delivery (particularly in tertiary health services) in Nigeria. Accordingly, this paper's main contribution is in its attempt to provide evidence within the scope of the research of the user fee policy of how user-fees impacts on clientele's access to care, willingness to utilize services and satisfaction with the quality of healthcare based on payment at the point of service by using a tertiary health centre in Delta State, Nigeria. However, it was not within the scope of the study to show the effectiveness of user-fees on changes in access, utilization rates or changes in outcomes based on the quality of care given. To this end, the findings identified in the research provide 'some degree of' evidence of how this policy impacts on healthcare delivery with a number of key issues identified.

First and foremost is with the mode of paying for health services in the facility. The findings reveal a mixture of the modes money was made available for payment. While the results revealed that this was through own monies (personal sources), contributions from relations or friends, borrowed monies or via pre-payments (health insurance), on the whole, about $98 \%$ of payment were through out-of pocket spending (OOPS) with most respondents having to source for funds from own monies. The OOPS in the facility is much higher than the average national OOPS placed at 65-70\%. [16] In fact, majority of the respondents had difficulty in accessing quality health services as they have to make 'formal' OOPS for health services. There were statistically significant associations with the formal OOPS and seeking health services. The study showed that borrowed monies $(\mathrm{p}=.001)$ and contributions from relatives ( $p=.032$ ) were the main contributions to the reason for not seeking tertiary health services in the facility. Although it was not within the scope of this study to investigate the cost of health services, findings from previous research reveals that financing mechanisms where formal charges are paid directly for a significant part of the cost of healthcare at the point of services restricts access to those who may be willing but not able to pay. $[17,18,19]$ Even though the study showed that for most of the respondents their travel time is less than an hour to the facility, it is possible that the thought of having to borrow and/or collect ('raise') money from family and friends as contributions for treatment brings a lot of concern to patients, and as such makes them hesitant to seek this level of care even when the need is obvious. It was also shown that marital status and level of income had statistically significant relationships with the decision to access health care in the facility. Being married and receiving an income of less than 109USD increases the chances of not accessing care. It was however, difficult to explain why marital status affects the decision to seek care. There is evidence showing that married couples have better health seeking behaviours [20], however, the observed relationship in this study could be due to rising competing house hold needs (which thereby exposes households to the financial risk of expensive illness at the time of need). Furthermore, with about 80\% (382 respondents) indicating that they do seek healthcare in the facility only when it is absolutely necessary, this study showed, that the challenge therefore is the extent of catastrophic healthcare financing from this policy as it can 
lead to inequities (both vertical and horizontal) in tertiary health coverage and other negative implications for the tertiary healthcare market.

Secondly, the authors attempted to show the willingness by patients to utilize available services to improve their health outcomes. While it was also not within the scope of this study to observe changes of the attendance rates in the hospital, the findings showed how user-fees policy affected clientele's use of available services. There were statistically significant relationships between payment methods and demanding recommended health services such as laboratory investigations etc. Own money, borrowed and contributed funds were associated to the difficulty in paying for all the services recommended by the physician $(\mathrm{p}<0.05)$. However, those paying via prepayment schemes did not show a statistically significant relationship with having difficulty in paying for all the needed services as recommended. This finding may have affected the utilization rates, as it could have a negative impact on the "quantitative" outcome of clientele-base in health services, particularly in country like Nigeria with high disease burden and low income per capita. On the contrary, findings from other studies such as in Uganda showed that when the policy was reversed there was a gradual increase from 0.56 per capita in 2002 to 0.79 per capita in the OPDs of health service centres [1].

Furthermore, assessing the quality of care showed that most the respondents felt satisfied with quality domains such as waiting time, patient centeredness, and performance or technical skill of service providers as well as the likelihood of improved outcomes. This study brought to the fore the fact that more respondents were on the average satisfied with the overall quality of care provided with having to pay at the point of service in most instances. It appears that pre-payment (health insurance) does not necessarily increase the quality of care given as this was not statistically significant with the level of satisfaction. Some authors have suggested that the administrative problems with pre-payment schemes so far has made them unattractive to hospital clientele and health care providers. [21] Additionally; the study revealed that despite the retrogressive nature of the financing mechanism, most respondents (83\%) were satisfied with the quality of care given. This could be explained from the fact that "having cash-in-hand" made these respondents pay for services and get their needed health outcome. However, we did not assess the relationship between socio-economic factors and the domains of quality of care given. Nevertheless, this study brought to the fore the fact that user-fees (or formal OOPS) negatively impacts on access and utilization of services but has little negative impact on the quality of care given. It could therefore be seen as an effective financing mechanism in terms of increasing the likelihood of desired health outcomes, while the problems of inequities and inefficiency with it continues.

\section{Conclusion}

The findings from this study has brought to the fore that user-fee policy is an effective mechanism for achieving desired health outcomes in tertiary care. However, there remain the problems of inequities (both vertical and horizontal) in tertiary health coverage. The evidence so far suggests that user fees alone will not accomplish universal health coverage or the sustainability objectives in health financing in the country. This suggests that charges levied for tertiary health services should therefore be linked to the broader package of financing through health insurance coverage. More so, there may be need to scale-up feeswaivers and exemptions for those who can't afford to pay for all their health service but 'desperately' need care to improve their health status. Ultimately, as commitments to improving healthcare delivery in Nigeria continue, policy makers and all stake holders in healthcare delivery should awaken to the responsibility of reforms in financing the tertiary health system in Nigeria.

\section{Acknowledgements}

The authors are grateful to God Almighty for his inspiration and the suggestions of the anonymous reviewers.

\section{Ethical Issues}

Ethical approval was given by the health research and ethics committee of Delta State University Teaching Hospital, Oghara Delta State.

\section{Competing Interests}

The authors declare that they have no competing interests. The views and opinions expressed in this article are those of the authors and do not reflect the official policy or position of any governmental agency.

\section{Authors' Contribution}

\section{U.J.E and I.S are the authors of the manuscript}

\section{References}

[1] Meessen B., Hercot D, Noirhomme M., Ridde V., Tibouti A, Bicaba A.,Kirunga C., Tashobya and Lucy Gilson. Removing user fees in the health sector: A Multi-Country Review. United Nations Children's Fund (UNICEF), 2009.

[2] Waiswa W.P. The impact of user fees on access to health services in low-and middle-income countries: RHL commentary (last revised: 1 May 2012). The WHO Reproductive Health Library; Geneva: World Health Organization.

[3] Guinness L and Wiseman V. Introduction to health economics. Open University Press. $2^{\text {nd }}$ Edition. 2011. 135-168.

[4] Uzochukwu BSC, Onwujekwe OE, Akpala CO. Effect of the Bamako-Initiative drug revolving fund on availability and rational use of essential drugs in primary health care facilities in Southeast Nigeria. Health Policy and Planning. 2002; 17 (4):378-383.

[5] Onwujekwe OE, Uzochukwu BSC, Obikeze EN, Okoronkwo I, Ochonma Og, Onoka CA, Madubuko G, Okoli C. Investigating determinants of out-of-pocket spending and strategies for coping with payments for healthcare in southeast Nigeria. BMC Health Services Research; 2010, Vol. 10, p 67.

[6] McPake B. User charges for health services in developing countries: a review of the economic literature. Social Science and Medicine, 1993. 36; 11: 1397-405.

[7] World Bank 1987. World Bank. Financing the health sector: an agenda for reform. Washington, DC: The World Bank, 1987. 
[8] Third World Network: World Bank and IMF are responsible for Africa's Health Crisis. 2002. Available online at $<$ http://www.twnside.org.sg/title/twe279g.htm> Accessed 6 ${ }^{\text {th }}$ July, 2013.

[9] Dumoublin, J., Kaddar M., Velasquez G. Access to Drugs and Finance: Basic Economic and Financial Analysis. WHO/DAP/91.5. Geneva: World Health Organization. 1991.

[10] Save the Children. User fees: paying for health services at the point of use. Position paper. London: Save the Children, UK, 2005.

[11] Commission for Africa. Our Common Interest: Report of the Commission for Africa. http://www.cfr.org/africa/ our-commoninterest-report-commission-africa/p8292. London: Commission for Africa, 2005.

[12] Oyibo PG. Out-of-pocket payment for health services: constraints and implications for government employees in Abakaliki, Ebonyi state, South east Nigeria. African Health Sciences 2011; 11 (3): 481-485

[13] Onwujekwe OE, Uzochukwu BSC, Okoli C, et al. Investigating determinants of out-of-pocket spending and strategies for coping with payments for healthcare in southeast Nigeria. BMC Health Services Research 2010, 10:67.

[14] Largade $\mathrm{M}$ and Palmer N. The impact of user fees on access to health services in low and middle-income countries. The Cochrane Collaboration. Published by John Wiley and Sons. 2011.
[15] Obansa SAJ and Orimisan A. Health Care Financing in Nigeria: Prospects and Challenges. Mediterranean Journal of Social Sciences. 2013. 4 (1); 224-225.

[16] Nyonator F, Kutzin J. Health for some? The effects of User fees in Volta Region of Ghana. Health Policy and Planning, 1999, 14 (4): 329-341.

[17] 18. Meessen B, Hercot D. Removing user fees in the health sector: a review of policy processes in six sub-Saharan African countries. Health Policy and Planning 2011; 26 (20):16-29.

[18] Ezeoke OP, Onwujekwe OE, Uzochukwu BSC. Towards Universal Coverage: Examining Costs of Illness, Payment, and Coping Strategies to Different Population Groups in Southeast Nigeria. Am. J. Trop. Med. Hygiene. 2012. 86 (1), 2012, pp. 52-57.

[19] Shaikh BT, Hatcher J. Health seeking behaviour and health service utilization in Pakistan: challenging the policy makers. Journal of Public Health 2004. 27: 1, pp. 49-54

[20] Criel B, Kegels G. A health insurance scheme for the hospital care in Bwamanda District, Zaire: lessons and questions after 10 years of functioning. Tropical Medicine and International Health. 1997. 2: 654-72. 